\title{
A experiência brasileira na erradicação da febre aftosa e o emprego do sistema I-ELISA 3ABC/EITB para certificação sanitária de bovinos e bubalinos
}

\author{
The Brazilian experience in the eradication of foot-and-mouth disease and the use \\ of I-ELISA 3ABC/EITB system for sanitary certification of bovine and buffaloes
}

\author{
Guilherme Henrique Figueiredo Marques', Eliana De Stefano², Cláudia Pestana Ribeiro², \\ Luis Henrique Aguilera Turissi², Ricardo Augusto Dias ${ }^{3}$, José Naranjo ${ }^{4}$, \\ Patrícia Silvia Pozzetti ${ }^{1}$, Jéssica Freire Costa ${ }^{2}$, Edviges Maristela Pituco ${ }^{2 *}$ \\ | | | | | | | | | | | | | | | | | | | | | | | | | | | | | | | | | | | | | | | | | | | | | | | | | | | | | | | | | | | | | | | | | | | | | | | | | | | | | | | | | | | | | | | | | | | | | | | | | | | | | | | | | | | | | | | | | | | | | | | | | | | | | | | | | | | | | | | | | | | | | | | | | | | | | | | | | | | | | | | | | | | | | | | | | | | | | | | | | | | | | | | | | | | | | | | | | | | | | | | | | | | |
}

RESUMO: A vacinação contra febre aftosa é ferramenta eficaz para erradicação e prevenção da doença, contudo, a presença de proteínas não capsidais (PNC) na vacina, produzidas durante a multiplicaçáo viral, tem sido o principal problema, visto que sua presença dificulta as açôes de vigilância, cuja busca se baseia na detecção de anticorpos contra essas proteínas para diferenciar animal vacinado de infectado. Por esse motivo, o Ministério da Agricultura, Pecuária e Abastecimento publicou em 2008 a Instrução Normativa no 50 (IN 50), que incluiu no controle da qualidade da vacina a pesquisa de anticorpos contra as PNC, para avaliar a retirada dessas proteínas. Considerando a interferência vacinal, objetivou-se avaliar a frequência de bovinos reagentes às PNC, analisada pelo sistema I-ELISA 3ABC/EITB, no Laboratório de Viroses de Bovídeos do Instituto Biológico de São Paulo, no período de 2002 a 2012. Dos 34.705 bovinos examinados, observou-se que a proporção de reagentes às PNC aumentou com a idade, evidenciando aumento da frequência de reagentes em animais que receberam maior número de vacinações, indicando interferência da vacinação na resposta às proteínas. Quando comparados antes e após a publicação da IN 50, observa-se diminuição da reatividade, com reduçấo, em 2010, de quase a metade em relaçáo a 2007, e ainda maior quando comparado com o período 2002 a 2006. Isso demonstra a efetividade da purificação da vacina em resposta ao cumprimento da IN 50, embora permaneça alguma sororreatividade em bovinos com múltiplas vacinaçôes. O sistema I-ELISA 3ABC/EITB demonstrou ser uma ótima ferramenta para impedir a movimentação de possíveis portadores do vírus oriundos de rebanhos vacinados, desde que seja considerado todo o contexto sanitário e epidemiológico.

PALAVRAS-CHAVE: febre aftosa; Programa Nacional de Erradicação e Prevenção da Febre Aftosa; proteínas não estruturais; trânsito de bovídeos; imunodiagnóstico.

\begin{abstract}
Vaccination against foot-and-mouth disease is an effective tool for eradication and prevention of this disease. However, the presence of non-capsidal proteins (NCP) in the vaccine, produced during viral replication, has been the main problem, since their presence hamper the vigilance as its relies on the detection of antibodies against NCP to differentiate vaccinated from infected animals. Therefore, the Brazilian Ministry of Agriculture, Livestock and Supply published the Normative Instruction 50 (IN 50) that included the detection of antibodies against the NCP to evaluate the removal of these proteins. Considering the vaccine interference, this paper aimed to evaluate the frequency of reagents to NCP, analyzed by I-ELISA 3ABC/EITB system in the Laboratory of Bovine Viruses (LVB), Biological Institute (IB), São Paulo, SP, Brazil, from 2002 to 2012. Of the 34,705 cattle examined, it was observed that the proportion of reagents to NCP increased with age, indicating increased frequency of reagents in animals that received more vaccines, showing interference of proteins in response to vaccination. When compared before and after the publication of IN 50, there was decreased reactivity, with reduction in 2010, of nearly half compared to 2007, and even higher when compared with 2002 to 2006 . This shows the effectiveness of the purification of the vaccine in response to the implementation of IN 50, although it remains some seroreactivity in cattle with multiple vaccinations. The I-ELISA 3ABC/EITB system proved to be a great tool to prevent the movement of possible carriers of the virus derived from vaccinated herds, provided that all sanitary and epidemiological context are taken in consideration.
\end{abstract}

KEYWORDS: foot-and-mouth disease; National Program for the Eradication and Prevention of Foot-and-mouth Disease (PNEFA); non-structural proteins; bovine transit; immune diagnosis.

\footnotetext{
'Departamento de Saúde Animal, Secretaria de Defesa Agropecuária, Ministério da Agricultura, Pecuária e Abastecimento (MAPA) - Brasília (DF), Brasil. ${ }^{2}$ Laboratório de Viroses de Bovídeos, Centro de Pesquisa e Desenvolvimento de Sanidade Animal, Instituto Biológico - São Paulo (SP), Brasil.

${ }^{3}$ Faculdade de Medicina Veterinária e Zootecnia da Universidade de São Paulo (USP) - São Paulo (SP), Brasil.

${ }^{4}$ Centro Pan-americano de Febre Aftosa (PANAFTOSA) - Duque de Caxias (RJ), Brasil.

${ }^{5}$ Superintendência Federal de Agricultura no Estado de São Paulo (SFA-SP) - São Paulo (SP), Brasil.

*Autor correspondente: pituco@biologico.sp.gov.br

Recebido em: 18/04/2013. Aceito em: 09/12/2014.
} 


\section{INTRODUÇÃO}

A febre aftosa foi identificada na América do Sul em 1870 devido ao incremento das importaçóes de bovinos pelos colonizadores quando ocorria uma epidemia no continente europeu, onde já era conhecida desde 1546. A doença foi registrada inicialmente na Argentina, de onde se propagou para o centro do país, posteriormente para a regiáo central do Chile, para o Uruguai e para a regiâo sul do Brasil, especificamente no estado do Rio Grande do Sul. Devido à ausência de controles sanitários, a doença se difundiu e em meados de 1895 foi registrada no Triângulo Mineiro, de onde passou para o estado de São Paulo (Lyra, 2003).

A luta contra a febre aftosa no Brasil, de forma organizada e oficial, vem se desenvolvendo desde 1969, embora desde 1934 o Ministério da Agricultura tenha regulamentado o Serviço de Defesa Sanitária Animal, por meio do Decreto no 24.548, que já contemplava algumas medidas de controle da doença. Em 1950 foram estabelecidas as Instruçóes de Profilaxia da Febre Aftosa.

Desde entấo, vários foram os esforços para erradicar essa doença: investimentos em infraestrutura, laboratórios, qualificaçáa do corpo técnico, desenvolvimento e fabricação de vacinas, campanhas de vacinação e fiscalização, entre outras medidas que permitiram ao país atingir reduçóes significativas no número de focos da febre aftosa e conquistar grandes áreas livres da doença (Souza et al., 1994).

Em 1992, o Programa de Controle da Febre Aftosa foi modificado para Programa de Erradicaçáo da Febre Aftosa (PNEFA), para tanto foi institucionalizado o Conselho Consultivo envolvendo representantes da sociedade, sendo sugerida a revisão das estratégias adotadas (BRASIL, 1992). Tal decisáo se sustentou no conceito da regionalização, aprovada pela Organização Mundial de Saúde Animal (OIE), que permitiu a criaçáo gradativa de zonas livres de febre aftosa, levando em conta o predomínio geográfico dos sistemas de produção e a interdependência desses sistemas em relaçáo ao processo de comercializaçáo dos bovinos e de seus produtos e subprodutos (Souza et al., 1994; OIE 2014).

Dessa forma foi possível o Brasil avançar no processo de erradicação com a adoção de regiốes livres da doença, sempre protegidas por barreiras naturais e/ou postos fixos e volantes de fiscalização, seguindo o sentido do sul para o norte do país (BRASIL, 2013a). A classificação adotada para definir a condiçáo sanitária de cada regiáo foi: zona livre de febre aftosa sem vacinação (Santa Catarina), zona livre de febre aftosa com vacinaçáo, zona tampáo e de alta vigilância e zona não livre. A Figura 1 demonstra a evolução cronológica dessas áreas, bem como a suspensão temporária da condição sanitária alcançada devido à reintroduçáo da febre aftosa (BRAsil, 2013a).

A Instrução Normativa no 44 , de 2 de outubro de 2007, define as diretrizes gerais para erradicaçáo e prevenção da febre aftosa a serem observadas em todo o território nacional, visando à implementação do PNEFA (Brasil, 2007a), conforme estabelecido pelo Sistema Unificado de Atenção à Sanidade Agropecuária (SUASA) (Brasil, 2006).

Considerando que o principal fator associado com a ocorrência e disseminação do vírus da febre aftosa é a movimentaçáo de bovinos infectados (Pituco et al., 2011), medidas como isolamento de bovinos na origem e no destino, além de análise clínica e exames laboratoriais são essenciais para mitigar o risco de introdução do vírus em áreas consideradas livres da doença (Brasil, 2007a).

O Quadro 1 mostra a situação sanitária da febre aftosa nos estados brasileiros e respectivos rebanhos, desenvolvido pelo Departamento de Saúde Animal (DSA) do Ministério da Agricultura, Pecuária e Abastecimento (MAPA), segundo informaçôes dos serviços veterinários oficiais dos estados (Cosalfa, 2011).

Com base nos princípios internacionais que regem o estabelecimento de zonas livres para febre aftosa, expressos no Código Sanitário (OIE, 2014) e no Acordo sobre Aplicação de Medidas Sanitárias e Fitossanitárias da Organização Mundial de Comércio (WTO, 2015), a zona livre brasileira é independente em relação às zonas ainda não livres, havendo rígido controle do ingresso de bovinos susceptíveis e de seus produtos e subprodutos.

Desta forma, a política geral do PNEFA, cujas diretrizes foram publicadas pelo MAPA, restringe o ingresso, na zona livre de febre aftosa, de bovinos suscetíveis à doença procedentes de outras unidades da federação ou países com condição sanitária inferior. Quando excepcionalmente houver necessidade de autorizar o ingresso de bovinos susceptíveis e de seus produtos e subprodutos, essa autorizaçáo somente poderá ocorrer sob condiçôes rigorosas e estrita de garantias de proteção da zona livre. Essa autorizaçáo, prévia e específica para cada caso, é expedida pelo DSA, através do serviço da área competente na Superintendência Federal de Agricultura (SFA) no estado de destino dos bovinos, após realização de análise de risco (BrasiL, 2007a).

Em qualquer circunstância, mesmo que as avaliaçóes indiquem um risco muito baixo, para ser autorizado o ingresso de bovinos susceptíveis para a área livre, esses deveráo ser submetidos à quarentena e ao diagnóstico laboratorial para avaliaçấo da condiçấo sanitária do animal na origem. Se os resultados forem negativos às provas diagnósticas, será autorizado o ingresso dos bovinos, que deverão ser submetidos à nova quarentena e análise laboratorial no destino. $\mathrm{O}$ ingresso destes, quando permitido, ocorre em caminhôes lacrados, limpos e desinfetados, através somente dos postos fixos de fiscalização e rotas previamente definidas pelas autoridades sanitárias (BRASIL, 2007a).

Desde o inicio da implantação de áreas livres de febre aftosa no Brasil, em 1998, foram analisadas milhares 


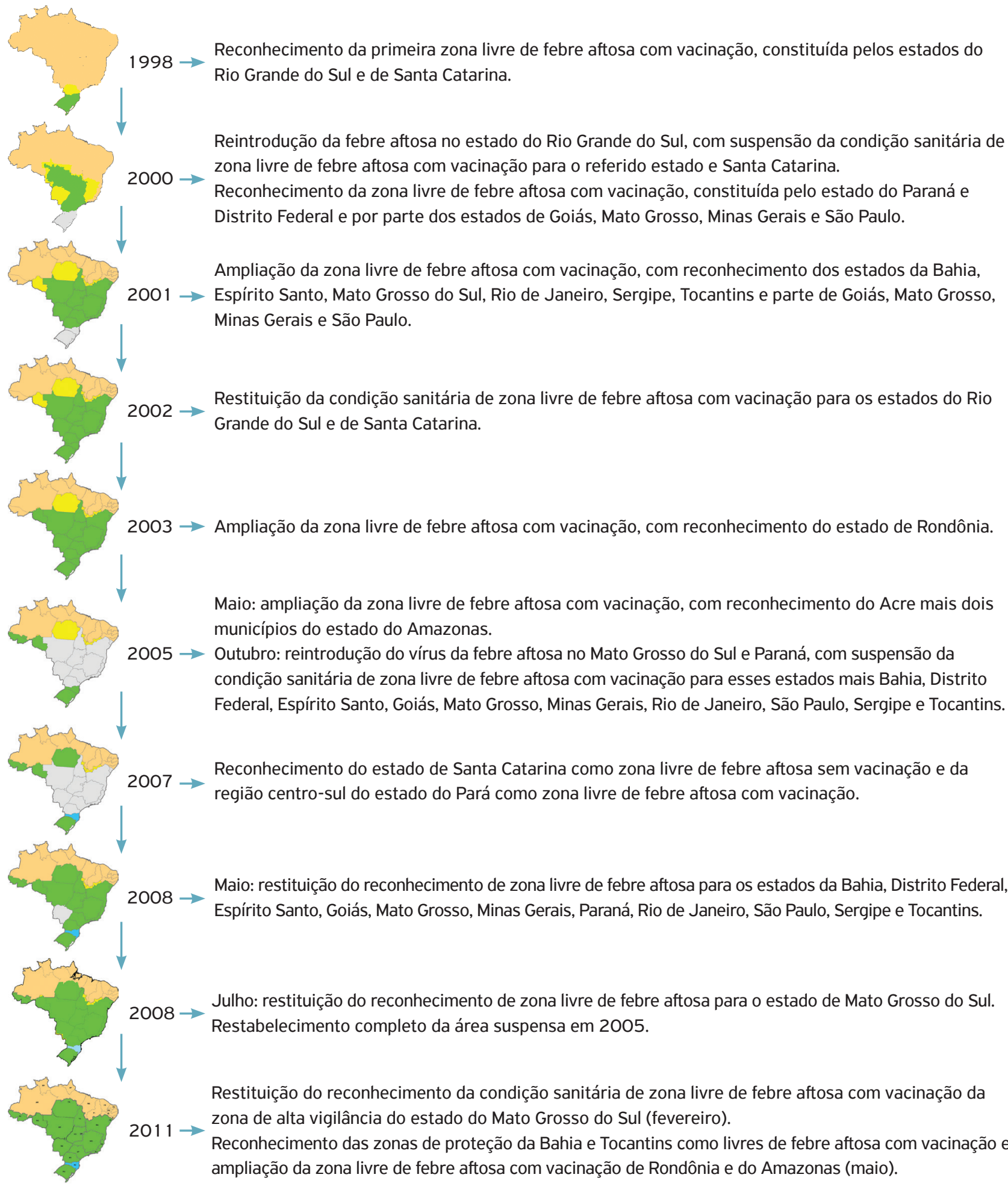

Zona livre sem vacinação

Zona livre com reconhecimento suspenso

Zona livre com vacinação

Zona infectada

Zona tampão

Fonte: BRASIL, $2013 \mathrm{a}$.

Figura 1. Evolução cronológica das zonas reconhecidas livres de febre aftosa pela Organização Mundial de Saúde Animal, Brasil, 1998 a 2011. 
de amostras para a finalidade descrita anteriormente, e para fazer frente a essas demandas, bem como exigências dos mercados importadores de bovinos e material genético, o MAPA, por meio da Coordenação Geral de Apoio Laboratorial (CGAL), credenciou diversos laboratórios públicos para realizarem esses diagnósticos (Brasil, 2013b).

Para a realizaçáo de exames sorológicos com vistas à movimentação de bovinos, foram credenciados, para realizar a prova de I-ELISA 3ABC/EITB, laboratórios oficiais como o Instituto Biológico (IB) em Sáo Paulo e o Instituto Mineiro de Agropecuária (IMA) de Minas Gerais (Brasil, 2009; BRASIL, 2010)

\section{Programa Nacional de Erradicação e Prevenção da Febre Aftosa}

Atualmente, as diretrizes gerais para erradicação e prevenção da febre aftosa observadas em todo o território brasileiro, com vistas à implementação do PNEFA, estão alicerçadas na Instrução Normativa no 44, de 2 de outubro de 2007 (Brasil, 2007a). A vacinação sistemática da população bovina e bubalina, o controle da movimentação animal, a vigilância epidemiológica, incluindo açôes de prevenção, e os planos de intervenção diante de emergências são os principais fundamentos do PNEFA, que se sustentam no compartilhamento de responsabilidades entre o setor público federal e estadual e o setor privado.

Quadro 1. Total de bovinos e búfalos por unidade da federação, de acordo com a classificação sanitária para febre aftosa, Brasil, 2011 .

\begin{tabular}{|c|c|c|c|c|}
\hline Unidade da federação & Área $\left(\mathrm{km}^{2}\right)$ & $\begin{array}{c}\text { População total } \\
\text { de bovinos }\end{array}$ & $\begin{array}{c}\text { População total } \\
\text { de bubalinos }\end{array}$ & Total \\
\hline \multicolumn{5}{|l|}{ Zona não livre } \\
\hline Alagoas & 27.768 & 1.257 .241 & 921 & 1.258 .162 \\
\hline Amapá & 142.815 & 53.022 & 217.882 & 270.904 \\
\hline Amazonas & 1.527 .493 & 745.885 & 69.685 & 815.570 \\
\hline Ceará & 148.826 & 2.589 .655 & 2.209 & 2.591 .864 \\
\hline Maranhão & 331.983 & 7.194 .459 & 78.363 & 7.272 .822 \\
\hline Pará* & 579.555 & 4.112 .747 & 427.237 & 4.539 .984 \\
\hline Paraíba & 56.440 & 1.506 .491 & 1.253 & 1.507 .744 \\
\hline Pernambuco & 98.312 & 2.401 .962 & 8.774 & 2.410 .736 \\
\hline Piauí & 251.529 & 1.757 .355 & 614 & 1.757 .969 \\
\hline Rio Grande do Norte & 52.797 & 766.646 & 1.176 & 767.822 \\
\hline Roraima & 224.299 & 704.264 & 306 & 704.570 \\
\hline Total da zona não livre & 3.441 .816 & 23.567 .916 & 808.574 & 23.898 .147 \\
\hline \multicolumn{5}{|l|}{ Zona livre } \\
\hline Acre & 152.581 & 2.531 .830 & 2.233 & 2.534 .063 \\
\hline Amazonas & 43.253 & 478.189 & 154 & 478.343 \\
\hline Bahia & 564.693 & 11.298 .271 & 26.126 & 11.324 .397 \\
\hline Distrito Federal & 5.802 & 98.714 & 573 & 99.287 \\
\hline Espírito Santo & 46.078 & 2.212 .845 & 2.970 & 2.215 .815 \\
\hline Goiás & 340.087 & 22.675 .249 & 51.409 & 22.726 .658 \\
\hline Mato Grosso & 903.358 & 29.177 .043 & 16.276 & 29.193 .319 \\
\hline Mato Grosso do Sul & 357.125 & 21.142 .295 & 14.610 & 21.156 .905 \\
\hline Minas Gerais & 586.528 & 23.856 .522 & 41.058 & 23.897 .580 \\
\hline Pará* & 668.135 & 14.930 .775 & 12.877 & 14.943 .652 \\
\hline Paraná & 199.315 & 9.505 .441 & 25.387 & 9.530 .828 \\
\hline Rio de Janeiro & 43.696 & 2.080.791 & 5.953 & 2.086 .744 \\
\hline Rio Grande do Sul & 281.749 & 13.648 .518 & 69.155 & 13.717 .673 \\
\hline Rondônia & 237.576 & 12.068 .525 & 5.837 & 12.074 .362 \\
\hline Santa Catarina & 95.346 & 4.022 .505 & 11.788 & 4.034 .293 \\
\hline São Paulo & 248.209 & 11.205 .668 & 74.925 & 11.280 .593 \\
\hline Sergipe & 21.910 & 1.183 .066 & 375 & 1.183 .441 \\
\hline Tocantins & 277.621 & 7.990 .093 & 8.254 & 7.998 .347 \\
\hline Total zona livre & 5.073 .062 & 189.628 .151 & 369.806 & 189.997 .957 \\
\hline Total geral & 8.514 .877 & 213.196 .067 & 1.178 .380 & 214.374 .447 \\
\hline
\end{tabular}

*Parte do estado do Pará em zona livre e parte em zona não livre.

Fonte: 39a Reunião Ordinária da Comissão Sul-Americana para a Luta contra a Febre Aftosa (COSALFA 2012). 
Em 1965 foi implantado no estado do Rio Grande do Sul o Programa de Combate à Febre Aftosa, que, um ano depois, foi estendido aos estados de Santa Catarina, Paraná, São Paulo, Minas Gerais, Bahia, Espírito Santo, Mato Grosso, Goiás, Rio de Janeiro e Sergipe (Souza et al., 1994).

Em 1992, profissionais do MAPA, das secretarias estaduais de agricultura e representantes de segmentos da cadeia produtiva da bovinocultura, com a assessoria do Centro Panamericano de Fiebre Aftosa (PANAFTOSA) de la Organización Panamericana de la Salud/Organización Mundial de la Salud (OPS/OMS), revisaram a política e as estratégias de combate à febre aftosa, visando a sua erradicação. As açôes foram regionalizadas, formando circuitos pecuários, sendo incorporada a participaçáo de produtores, agroindústrias, comércio, universidades, em todas as fases e aspectos do Programa (Souza et al., 1994).

Os circuitos pecuários foram fundamentados na relaçâo existente entre o predomínio geográfico dos sistemas de produção e a interdependência desses sistemas em relação ao processo de comercialização dos bovinos e de seus produtos e subprodutos. Cada um desses conjuntos de sistemas produtivos e comerciais (cria, recria e engorda), integrado em uma rede comercial, configura um circuito pecuário mais ou menos independente em relação aos demais circuitos. Dentro de cada circuito, os sistemas de produçáo mencionados estavam inter-relacionados sem função de dependências de criação, que se manifestam através dos fluxos de comercialização. Esses sistemas pecuários apresentavam uma forte correspondência com o grau de endemismo referente à ocorrência de febre aftosa. Isso permitiu caracterizar os ecossistemas da doença como endêmico primário (áreas extrativas), endêmico secundário (áreas de engorda), paraendêmicos (áreas leiteiras e de pequenos produtores) e indenes ou livres, destacando-se, à época, a prioridade do PNEFA para as áreas endêmicas (Souza et al., 1994).

\section{Campanha de vacinação}

No Brasil, é de responsabilidade dos proprietários a aquisição e a aplicação da vacina contra a febre aftosa, cabendo ao serviço veterinário oficial (SVO) garantir a qualidade da vacina produzida, bem como controlar, orientar e avaliar as atividades de comercialização e de utilização da vacina (Brasil, 2007a).

A vacinação contra febre aftosa é sistemática e obrigatória para as espécies bovinas e bubalinas em todo o território nacional (BRASIL, 2007b), exceto no estado de Santa Catarina, que náo vacina desde o ano 2000 (Brasil, 2000a e Brasil, 2000b). É proibida a vacinação para as demais espécies susceptíveis (suína, ovina e caprina), conforme o estabelecido na IN no 44/2007 (Brasil, 2007a). Por força da legislação vigente, somente o MAPA determina quando uma situação de emergência sanitária justifica a vacinação de outras espécies, ou quando o calendário de vacinação estabelecido previamente pode ser alterado (BRASIL, 2007a).
As experiências disponíveis na América do Sul demonstram que a manutenção de um adequado nível de imunidade populacional na espécie bovina representa condição necessária e suficiente para a erradicação da doença (BrasiL, 2005). As campanhas de vacinação no país são avaliadas pelos órgãos executores de defesa sanitária animal, considerando, principalmente, a declaração de vacinação apresentada pelos produtores rurais, responsáveis pela sua execução, contraposta ao cadastro de exploraçôes pecuárias disponível nas unidades veterinárias locais do SVO (BRASIL, 2005). Os resultados obtidos indicam cobertura imunitária para febre aftosa satisfatória na maior parte das unidades federativas integrantes da zona livre de febre aftosa com vacinação, sendo desenvolvidas açôes pontuais nas áreas que não atingiram a expectativa esperada pelo MAPA (Brasil, 2007c).

A evolução das coberturas de vacinação e a distribuiçắo anual de focos de febre aftosa no país, para o período de 1994 a 2012, podem ser avaliadas no Gráfico 1.

Após cada etapa, o proprietário dos bovinos deve registrá-la no escritório do SVO, dentro dos prazos estabelecidos. Finalizado esse prazo, o SVO identifica os produtores inadimplentes, que ficam sujeitos a multas e somente serão autorizados a movimentar seus animais após a vacinaçâo com acompanhamento oficial (BRASIL, 2007a). O MAPA desenvolve estudos periódicos que têm demonstrado que os níveis de proteçấo imunitária são compatíveis com os altos índices de registro da vacinação contra a febre aftosa no país (BrasIL, 2011).

\section{Estratégias de vacinação}

A vacinaçấo é obrigatória em todo o território nacional, exceto no estado de Santa Catarina, para bovinos e bubalinos, independentemente da idade, empregando-se as

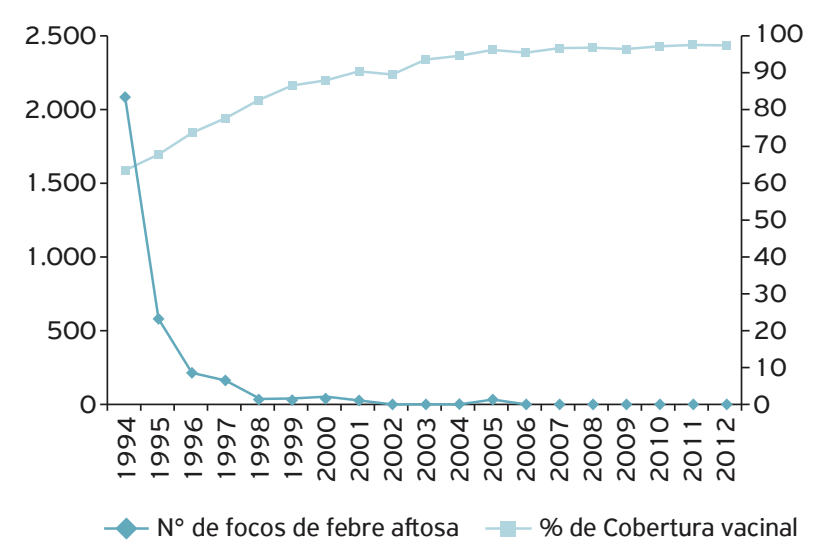

Fonte: MARQUES, 2013.

Gráfico 1. Número de focos de febre aftosa e percentual de cobertura de vacinação de 1994 a 2012. 
diferentes estratégias de vacinação, que variam de acordo com cada unidade federativa, considerando, principalmente, as condições climáticas predominantes, as estaçôes de concentração dos nascimentos de bezerros, a intensidade e a sazonalidade da movimentação ou da comercialização dos bovinos (BrasiL, 2007a).

As normas nacionais estabelecem a obrigatoriedade da vacinação durante as etapas previamente definidas de acordo com a condição sanitária de cada zona ou unidade da federação, sendo que qualquer vacinação fora do calendário oficial somente pode ser realizada mediante autorização prévia do SVO (Brasil, 2007a). Essas estratégias de vacinação podem ser resumidas em quatro tipos:

1. vacinação semestral de todo o rebanho bovino e bubalino em 30 dias, adotado na grande maioria das unidades federativas do Brasil;

2. vacinação semestral de bovinos e bubalinos com até 24 meses de idade e vacinação anual para bovinos com mais de 24 meses de idade, realizadas em etapas de 30 dias;

3. vacinação semestral de bovinos e bubalinos com até 24 meses de idade e vacinação anual para bovinos com mais de 24 meses de idade, com etapa de reforço adicional para bovinos com até 12 meses de idade, em etapas de 30 dias;

4. vacinação anual de todos os bovinos e bubalinos, em etapas que variam de 45 a 60 dias, realizadas em regióes onde as características geográficas só possibilitam o manejo dos bovinos durante período limitado do ano (Brasil, 2013a).

O MAPA define a mudança de estratégia de vacinação considerando a evolução do PNEFA, seguindo uma das possibilidades supra citadas no que diz respeito à vacinação, incluindo, se necessário, zonas de proteção, onde são intensificadas as vacinaçóes (BrasıL, 2014).

\section{MATERIAL E MÉTODOS}

Foram compilados os resultados de febre aftosa de bovinos, analisados pelo sistema I-ELISA 3ABC/EITB (BERGMANN et al., 2000), para detecção de anticorpos contra proteínas não capsidais, obtidos no período de 2002 a 2012, no Laboratório de Viroses de Bovídeos do Instituto Biológico (LVB/IB), de Sáo Paulo. Assim, a amostragem foi composta por 34.705 soros de bovinos, procedentes de 669 propriedades rurais. Um banco de dados foi criado no programa de computador Microsoft Office Excel ${ }^{\circ} 2007$, onde foram tabulados todos os resultados das análises laboratoriais

O LVB/IB recebe amostras de soro colhidas por veterinários de órgãos oficiais com o objetivo de certificação para o trânsito de animais e de material genético entre áreas de condição sanitária diferente para febre aftosa. Os resultados observados expressam a realidade nacional, uma vez que $96 \%$ de todos os testes feitos no país com a finalidade de movimentação são realizados nesse laboratório.

Os soros, quando enviados ao LVB/IB, estavam acompanhados do formulário específico, com as seguintes informaçóes individualizadas: origem e destino dos animais, finalidade, número de vacinaçóes, última vacina utilizada, data da última vacinação, data da colheita do sangue (número de colheitas, sorologia pareada), intervalo entre a vacinação e a colheita, faixa etária, idade, espécie, raça, sexo e resultados. Foram utilizadas as seguintes informaçóes: espécie, sexo, idade, ano de amostragem e número de vacinaçôes.

Foi realizada uma análise univariada através do teste do qui-quadrado $\left(\chi^{2}\right)$ utilizando as variáveis descritivas, testadas individualmente quanto à associação com a variável dependente (resultado positivo no protocolo de testes). O nível de significância para esse teste foi de $20 \%$.

As variáveis que apresentaram associação com a variável dependente foram selecionadas para a realização de uma análise múltipla utilizando regressão logística. Nessa análise, o nível de significância foi de $5 \%$. Os testes foram realizados no programa de computador SPSS 9.0, utilizando o método Enter.

Antes de serem submetidas às análises, foi feita a recodificação das variáveis qualitativas de acordo com uma ordem crescente de risco, de acordo com o nível de positividade observado. As categorias de menor risco foram denominadas de "categoria-base", portanto, não foram calculados odds ratio (OR) para essas categorias.

A variável qualitativa sexo, além das variáveis quantitativas contínuas idade e número de vacinaçóes foram utilizadas no formato original, sem recategorizaçóes. Somente as variáveis contínuas foram apresentadas ao modelo múltiplo sem a realização da análise univariada $\left(\chi^{2}\right)$. Suas distribuiçôes foram testadas através do teste de Kolmogorov-Smirnov e as medidas de tendência central (médias ou medianas) comparadas através de métodos paramétrico (teste t) ou não paramétrico (Mann-Whitney), na dependência do tipo de distribuição observada.

As amostras de bovinos analisadas eram de diversas idades e vacinaçóes, considerando que, quanto mais velho o bovino, maior seria o número de vacinações recebidas. As faixas etárias foram estratificadas da seguinte forma: estrato 1 (de 1 a 6 meses de idade); estrato 2 (de 7 a 12 meses de idade); estrato 3 (de 13 a 18 meses de idade); estrato 4 (de 19 a 24 meses de idade); estrato 5 (de 25 a 30 meses de idade); estrato 6 (acima de 31 meses de idade).

Foi testada a colinearidade das variáveis antes da apresentação ao modelo múltiplo de regressão logística, através do teste de correlação de Pearson (paramétrico) ou Spearman (não paramétrico), na dependência do tipo de distribuição observada. 
O período de análise de 2002 a 2012 foi dividido em três intervalos, levando em consideração a publicação da Instruçáo Normativa Ministerial no 50, de 23 de setembro de 2008, que obrigou todas as indústrias produtoras de vacina contra febre aftosa a produzirem imunógenos não indutores de anticorpos contra proteínas não capsidais (PNC) (BrasIL, 2008b):

1. entre 2002 e 2006, quando não era obrigatório que as vacinas não induzissem anticorpos contra PNC;

2. entre 2007 e 2009 , quando as indústrias reviram seus processos e buscaram a melhoria da vacina nesse quesito;

3. entre 2010 e 2012 , quando as vacinas já estavam atendendo às exigências da IN 50 (BrasiL, 2008b).

\section{RESULTADOS E DISCUSSÃO}

As questóes relacionadas às $\mathrm{PNC}$ do vírus da febre aftosa (VFA) são de importância estratégica para países que utilizam em seus programas de erradicação da doença a vacinação massiva e sistemática, e que necessitam demonstrar a proteção imunológica e a ausência da atividade viral na avaliação interna do programa e perante OIE e parceiros comerciais (OIE, 2015).

Para a manutenção das áreas livres e o ingresso de animais susceptíveis de uma área não livre, faz-se necessária a realização de testes para detecção de anticorpos contra PNC, que, em teoria, somente estariam presentes em animais que sofreram infecção natural. A experiência acumulada pelo Brasil e outros países indica que a presença desses anticorpos também pode estar associada à vacinação, devendo-se considerar que necessariamente não indica a infecção prévia, já que podem refletir resultado de múltiplas vacinaçóes pelo uso de vacinas com resíduo de PNC conforme alertaram inicialmente Lyra; CôrTEs (2007).

Níveis elevados da reatividade sorológica em bovinos de propriedades rurais foram observados entre 2002 e 2004 , o menor nível no período de 2005 a 2008, e diminuiu para níveis ainda mais baixos após o ano de 2009. Esse cenário é coincidente com a vigência da Instrução Normativa $\mathrm{n}^{\mathrm{o}} 50$ de 2008, que trata do controle da pureza de vacinas (Tabela 1 e Gráfico 2).

O Gráfico 3 mostra a evolução da reatividade por idade, em meses, dos bovinos procedentes de propriedades rurais. Foi observada alta reatividade nos seis primeiros meses, o que nos permite deduzir que se trata de imunidade passiva (colostro), seguido de um baixo nível de reatividade entre 6 e 16 meses, tendo em vista o baixo número de vacinaçôes, culminando com aumento sustentado na reatividade conforme o aumento da idade dos bovinos amostrados e, consequentemente, maior número de vacinaçôes. $\mathrm{O}$ mesmo ocorreu quando os bovinos foram agrupados por faixa etária (Tabela 2 e Gráfico 4).
Comparando o sexo e a faixa etária dos animais foi verificada alta reatividade para as PNC na faixa etária 1 e baixa entre as faixas 2 e 3, com elevaçáo e manutenção nas 4 a 6 , existindo uma clara diferença entre as respostas de acordo com o sexo (Tabela 3 e Gráfico 5).

Diferenças no sistema imune de fêmeas e machos náo são atribuídas unicamente às diferenças hormonais, mas com uma relaçáo com o cromossomo X. Nesse cromossomo existem vários genes que regulam a atividade do sistema imune (FIsH, 2008). Recentemente foi aberto um campo de investigação sobre o papel dos micro-RNAs (miRNAs) como imunomoduladores. Do total de miRNAs contidos no genoma humano, aproximadamente $10 \%$ sáo codificados pelo cromossomo $\mathrm{X}$ e nenhum cromossomo $\mathrm{Y}$. Isso sugere que os miRNAs podem influenciar a resposta imune, o que explicaria a diferença entre os sexos (PINHeiro et al., 2011).

Tabela 1. Distribuição cronológica da reatividade a anticorpos contra proteínas não capsidais do vírus da febre aftosa de bovinos de propriedades rurais, Laboratório de Viroses de Bovídeos do Instituto Biológico, 2002 a 2012 . São Paulo, 2014.

\begin{tabular}{lcccc}
\multirow{2}{*}{ Ano } & \multicolumn{2}{c}{ I-ELISA 3ABC/EITB } & Total & $\begin{array}{c}\% \\
\text { reagente }\end{array}$ \\
\cline { 2 - 3 } & Reagente & $\begin{array}{c}\text { Não } \\
\text { reagente }\end{array}$ & & \\
\hline 2002 & 290 & 1.006 & 1.296 & 22,4 \\
\hline 2003 & 71 & 450 & 521 & 13,6 \\
\hline 2004 & 1.139 & 6.027 & 7.166 & 15,9 \\
\hline 2005 & 75 & 787 & 862 & 8,7 \\
\hline 2006 & 341 & 3.327 & 3.668 & 9,3 \\
\hline 2007 & 613 & 4.262 & 4.875 & 12,6 \\
\hline 2008 & 136 & 1.862 & 1.998 & 6,8 \\
\hline 2009 & 45 & 2.292 & 2.337 & 1,9 \\
\hline 2010 & 151 & 5.314 & 5.465 & 2,8 \\
\hline 2011 & 130 & 2.258 & 2.388 & 5,4 \\
\hline 2012 & 68 & 4.061 & 4.129 & 1,6 \\
\hline Total & 3.059 & 31.646 & 34.705 & 8,8 \\
\hline
\end{tabular}

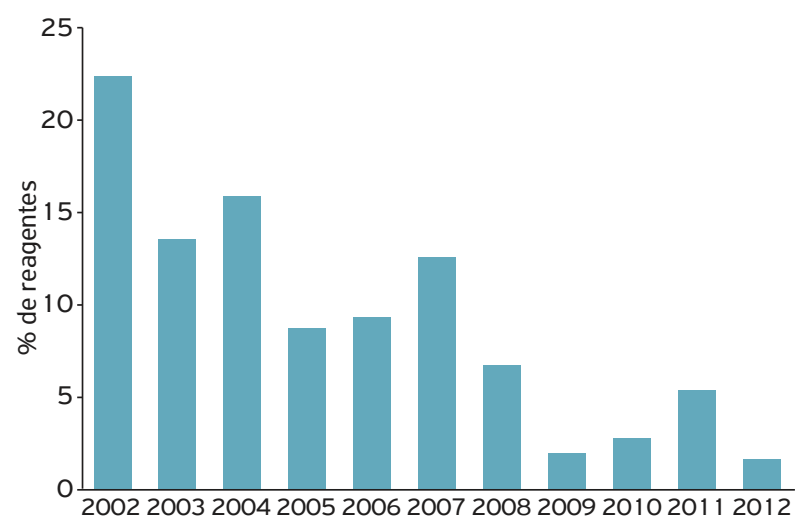

Gráfico 2. Percentual de bovinos de propriedades rurais com anticorpos contra proteínas não capsidais do vírus da febre aftosa segundo o ano. Laboratório de Viroses de Bovídeos do Instituto Biológico, 2002 a 2012 . São Paulo, 2014. 


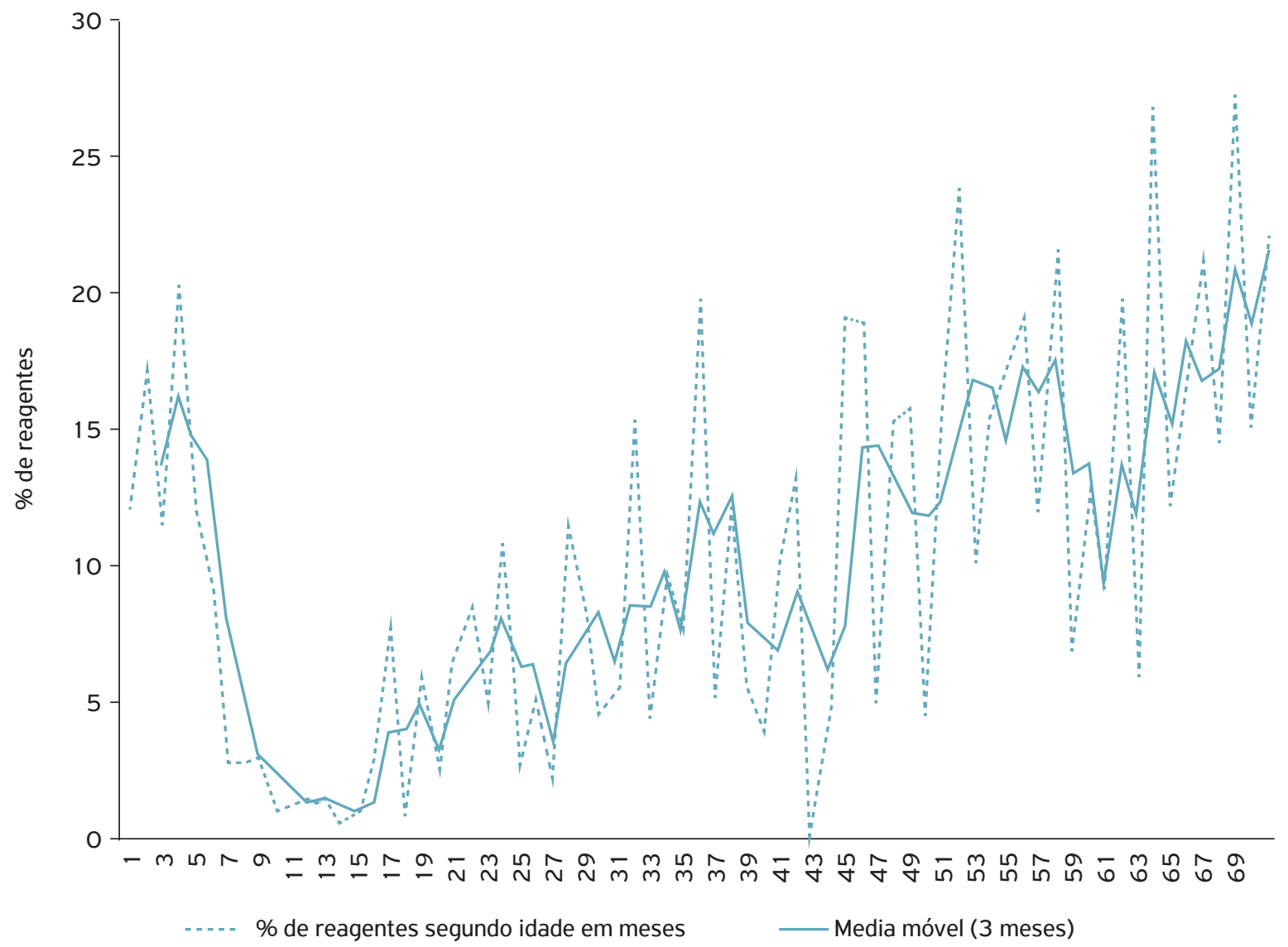

Gráfico 3. Percentual de bovinos com anticorpos contra as PNC segundo idade. LVB, 2002 a 2012. São Paulo, 2014.

Tabela 2. Frequência de bovinos de propriedades rurais com anticorpos contra proteínas não capsidais do vírus da febre aftosa por faixa etária, Laboratório de Viroses de Bovídeos do Instituto Biológico, 2002 a 2012 . São Paulo, 2014.

\begin{tabular}{|c|c|c|c|c|}
\hline \multirow{2}{*}{$\begin{array}{l}\text { Faixa etária } \\
\text { (meses) }\end{array}$} & \multicolumn{2}{|c|}{ I-ELISA 3ABC/EITB } & \multirow[b]{2}{*}{ Total } & \multirow{2}{*}{$\begin{array}{c}\% \\
\text { reagente }\end{array}$} \\
\hline & Reagente & $\begin{array}{l}\text { Não } \\
\text { reagente }\end{array}$ & & \\
\hline $1(<6)$ & 411 & 2.477 & 2.888 & 14,2 \\
\hline $2(7$ a 12$)$ & 79 & 4.463 & 4.542 & 1,7 \\
\hline $3(13$ a 38$)$ & 445 & 7.099 & 7.544 & 5,9 \\
\hline $4(19$ a 24$)$ & 1.155 & 7.742 & 8.897 & 13,0 \\
\hline $5(25$ a 30$)$ & 140 & 1.568 & 1.708 & 8,2 \\
\hline $6(>31)$ & 479 & 5.037 & 5.516 & 8,7 \\
\hline Total & 2.709 & 28.386 & 31.095 & 8,7 \\
\hline
\end{tabular}

Quando se comparou sexo com o número de vacinaçóes, observou-se que a reatividade das fêmeas foi muito superior em relação aos machos, em particular a partir da terceira vacinação, destacando essa discrepância também na quinta e sétima vacinação, quando, coincidentemente, em média, as fêmeas estão maduras sexualmente (Gráfico 6).

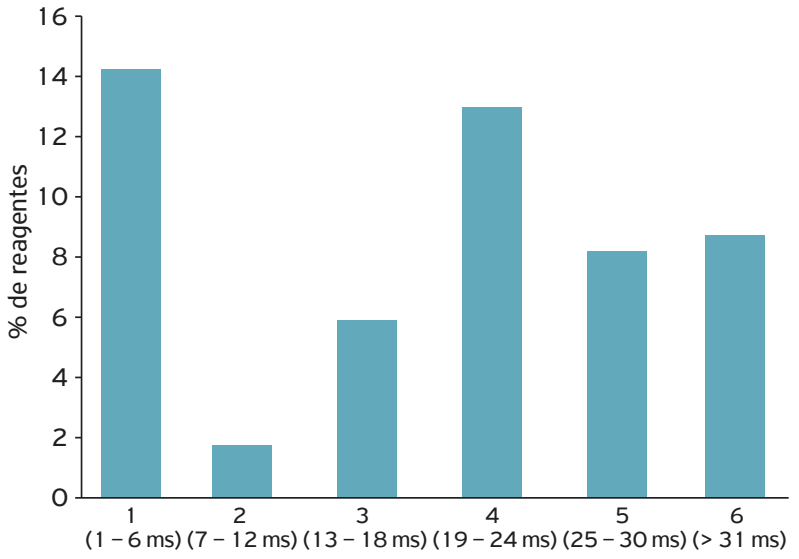

ms: meses

Gráfico 4. Percentual de bovinos de propriedades rurais com anticorpos contra proteínas não capsidais do vírus da febre aftosa por faixa etária, Laboratório de Viroses de Bovídeos do Instituto Biológico 2002 a 2012. São Paulo, 2014.

Observa-se uma diminuição da reatividade no decorrer do período estudado, tanto para fêmeas como para os machos, havendo uma redução em 2010 de quase a metade em relação 
Tabela 3. Frequência de bovinos de propriedades rurais com anticorpos contra proteínas não capsidais do vírus da febre aftosa, por sexo, Laboratório de Viroses de Bovídeos do Instituto Biológico, 2002 a 2012. São Paulo, 2014.

\begin{tabular}{lcccc} 
& \multicolumn{2}{c}{ I-ELISA 3ABC/EITB } & Total & $\begin{array}{c}\% \\
\text { Sexo }\end{array}$ \\
\cline { 2 - 4 } & Reagente & $\begin{array}{c}\text { Não } \\
\text { reagente }\end{array}$ & reagente \\
Macho & 464 & 12.105 & 12.569 & 11,81 \\
\hline Fêmea & 2.478 & 18.511 & 20.989 & 3,69 \\
\hline Não informado & 117 & 1.030 & 1.147 & 10,02 \\
\hline Total & 3.059 & 31.646 & 34.705 & 8,81
\end{tabular}

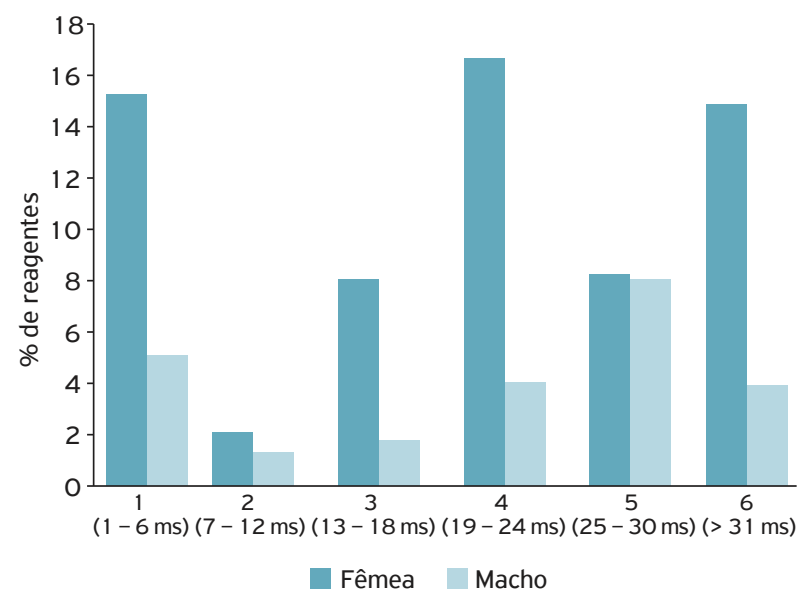

ms: meses

Gráfico 5. Percentual de bovinos de propriedades rurais com anticorpos contra proteínas não capsidais do vírus da febre aftosa, por faixa etária e sexo, Laboratório de Viroses de Bovídeos do Instituto Biológico, 2002 a 2012. São Paulo, 2014.

a 2007, e muito inferior em relação ao período compreendido entre 2002 e 2006. Isso demonstra os esforços dos laboratórios para purificar as vacinas contra febre aftosa, tendo em vista a necessidade e as cobranças legais (Gráfico 7).

\section{CONCLUSÕES}

Apesar do sistema I-ELISA 3ABC/EITB ter sido validado para bovinos e búfalos com menos de 24 meses, esse ainda é o melhor método de diagnóstico para impedir a movimentação de possíveis portadores do vírus da febre aftosa oriundos de rebanhos vacinados independentemente da idade, desde que seja considerado todo o contexto sanitário

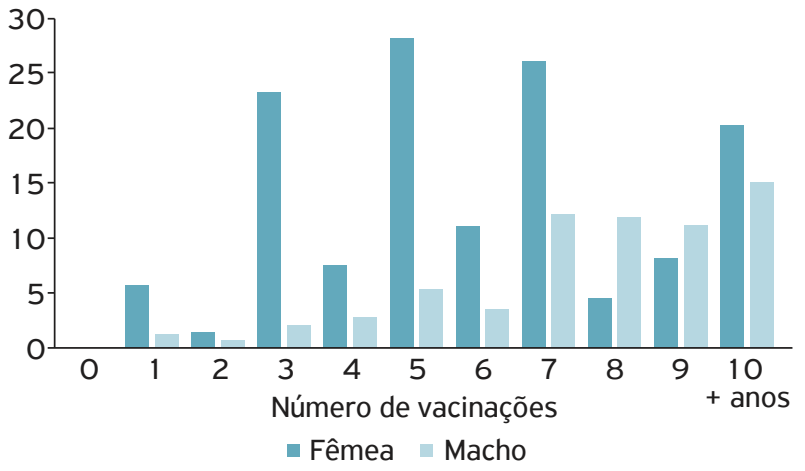

Gráfico 6. Percentual de bovinos de propriedades rurais com anticorpos contra PNC do vírus da febre aftosa segundo sexo e numero de vacinações, LVB/IB, 2002 a 2012. São Paulo, 2014.

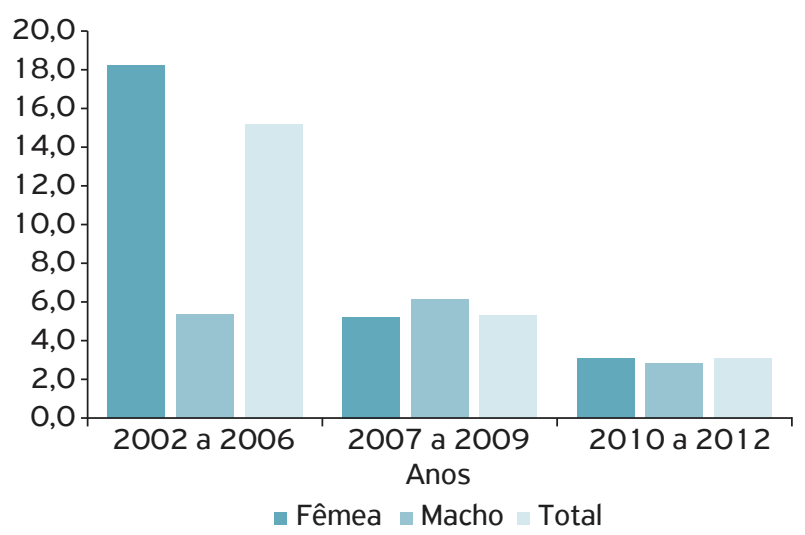

Gráfico 7. Percentual de bovinos de propriedades rurais com anticorpos contra PNC do vírus da febre aftosa segundo sexo e intervalo temporal, LVB/IB, 2002 a 2012. São Paulo, 2014.

e epidemiológico envolvido. Considerando o período em estudo, a proporção de animais sororreagentes no sistema I-ELISA 3ABC/EITB aumentou conforme o número de vacinaçôes. Os bovinos com menos de 6 meses de idade tiveram alta taxa de reatividade às PNC do VFA, o que é indicativo de imunidade passiva (ingestão de colostro) proveniente de fêmeas multivacinadas. Os resultados sugerem a efetividade do cumprimento da Instrução Normativa $\mathrm{N}^{\circ}$ 50, no que diz respeito à redução da interferência vacinal em testes diagnósticos para a febre aftosa no Brasil. O ciclo hormonal das fêmeas parece interferir diretamente na capacidade de resposta aos anticorpos contra PNC do VFA, necessitando de investigaçóes no aprofundamento da questão, sob condições controladas e não somente com amostras de conveniência. 


\section{REFERÊNCIAS}

BERGMANN, I.E.; MALIRAT, V.; NEITZERT E.; BECK, E.; PANIZZUTTI, N.; SÁNCHEZ, C.; FALCZUK, A. Improvement of serodiagnostic strategy for foot-and-mouth disease virus surveillance in cattle under systematic vaccination: a combined system of an indirect ELISA-3ABC with an enzyme-linked immunoelectrotransfer blot assay. Archives of Virology, v.145, n.3, p.473-489, 2000.

BRASIL. Ministério da Agricultura e Reforma Agrária. Portaria da Secretaria de Defesa Agropecuária no 182, de 16 de julho de 1992. Cria o Conselho Consultivo do Projeto de Controle das Doenças Animais nos aspectos relacionados à febre aftosa. Brasília: Diário Oficial da União; 1992.

BRASIL. Ministério da Agricultura e Reforma Agrária. Portaria da Secretaria de Defesa Agropecuária n 153, de 27 de abril de 2000. Declara a área formada pelos Estados de Santa Catarina e do Rio Grande do Sul, como Zona Livre de Febre Aftosa, sem vacinação. Brasília: Diário Oficial da União; 2000a.

BRASIL. Ministério da Agricultura, Pecuária e Abastecimento. Instrução Normativa no 13 , de 19 de maio de 2000. A Secretaria de Defesa Agropecuária, visando à proteção Zona Livre de Febre Aftosa, sem vacinação estabelece as normas, para o cumprimento da Portaria no 153 de 27 de abril de 2000. Brasília: Diário Oficial da União; 2000b.

BRASIL. Ministério da Agricultura, Pecuária e Abastecimento. Departamento de Saúde Animal. Orientações para fiscalização do comércio de vacinas contra a febre aftosa e para controle e avaliação das etapas de vacinação. Brasília: DSA; 2005. 31 p. Disponível em: <http://www.agricultura.gov.br/arq_editor/ file/Aniamal/programa\%20nacional\%20sanidade\%2Oaftosa/ orientacao\%20para\%20fiscalizacao.pdf $\geq$. Acesso em: 03 abr. 2014.

BRASIL. Ministério da Agricultura, Pecuária e Abastecimento. Decreto № 5.741, de 30 de março de 2006. Regulamenta os arts. 27-A, 28-A e 29-A da Lei n 8.171, de 17 de janeiro de 1991, organiza o Sistema Unificado de Atenção à Sanidade Agropecuária, e dá outras providências. Brasília: Diário Oficial da União; 2006.

BRASIL. Ministério da Agricultura, Pecuária e Abastecimento. Instrução Normativa no 44, de 02 de outubro de 2007. Aprova diretrizes gerais para erradicação e prevenção da febre aftosa, a serem observados em todo o Território Nacional com vistas a implementação do PNEFA conforme estabelecido pelo SUASA. Brasília: Diário Oficial da União; 2007a.

BRASIL. Ministério da Agricultura, Pecuária e Abastecimento. Instrução Normativa n 53, de 23 de novembro de 2007. Reconhece e consolida a situação sanitária das vinte e sete Unidades da Federação com respeito à Febre aftosa. Brasília: Diário Oficial da União; 2007b.

BRASIL. Ministério da Agricultura, Pecuária e Abastecimento. Avaliação da imunidade populacional resultante das campanhas de vacinação contra a febre aftosa. Relatório final. Brasília: PNEFA; 2007c. Disponível em: <http://www.agricultura.gov.br/arq_editor/
file/Aniamal/programa\%20nacional\%20sanidade\%20aftosa/ avaliacao\%20da\%20imunidade.pdf>. Acesso em: 03 abr. 2014

BRASIL. Ministério da Agricultura, Pecuária e Abastecimento. Instrução Normativa Ministerial n 50 , de 23 de setembro de 2008. Aprova o regulamento técnico para a produção, controle da qualidade, comercialização e emprego de vacinas contra a febre aftosa. Brasília: Diário Oficial da União; 2008b.

BRASIL. Ministério da Agricultura, Pecuária e Abastecimento. Credenciamento do laboratório do Instituto Mineiro de Agropecuária. Portaria № 38 de 05 de fevereiro de 2009. Brasília: Diário Oficial da União; 2009. Disponível em: http://www.agricultura.gov.br/ arq_editor/file/Aniamal/Laborat\%C3\%B3rios/IN\%2057-2013/ DIA/MG/Modelo\%20para\%20P\%C3\%A1 gina\%20-\%20IN\%20 57\%20IMA\%2028-08-14.pdf. Modelo para Página - IN 57 IMA 28-08-14. Acesso em: 03 abr. 2014.

BRASIL. Ministério da Agricultura, Pecuária e Abastecimento. Credenciamento do laboratório do Instituto Biológico de São Paulo, 2010. Brasília: Diário Oficial da União; 2014. Portaria: 189, de 28/07/2014 D.O.U: 143, de 29/07/2014, Seção 1, pág.: 4.

BRASIL. Ministério da Agricultura, Pecuária e Abastecimento. Monitoramento Sorológico para avaliação da eficiência da vacinação contra a febre aftosa na zona livre. 2011 Disponível em: <http://www.agricultura.gov.br/arq_editor/file/Relatorio_ avaliacao_eficiencia_vacinal_ZL_2010_final_2.pdf >. Acesso em: 03 abr. 2014.

BRASIL. Ministério da Agricultura, Pecuária e Abastecimento. Mapas da Situação da Febre Aftosa no Brasil. Evolução geográfica do processo de implantação de zona livre de febre aftosa no Brasil. Brasília: MAPA; 2013a. Disponível em: <http://www. agricultura.gov.br/arq_editor/file/Evolu\%C3\%A7\%C3\%A30\%20 \%С3\%A 1 rea\%20livre\%20mai\%202014.pdf>. Acesso em: 03 abr. 2014

BRASIL. Ministério da Agricultura, Pecuária e Abastecimento. Instrução Normativa ${ }^{\circ}$ 57, de 11 de dezembro de 2013. Aprovar critérios para credenciamento, reconhecimento, extensão de escopo e monitoramento de laboratórios. Brasília: Diário Oficial da União; 2013b.

BRASIL. Ministério da Agricultura, Pecuária e Abastecimento. Mapas da Situação da Febre Aftosa no Brasil. Mapa das estratégias de vacinação adotadas no Brasil - 2013. . Brasília: MAPA; 2013b. Disponível em: <http://www.agricultura.pr.gov.br/arquivos/File/ PDF/in_1_07_anexo.pdf>. Acesso em: 03 abr. 2014.

BRASIL. Ministério da Agricultura, Pecuária e Abastecimento. Calendário Nacional de Vacinação contra Febre Aftosa. 2014. Disponível em: http://www.agricultura.gov.br/arq_editor/file/ Calend\%C3\%A 1 rio\%20de\%20Vacina\%C3\%A7\%C3\%A3o_ abr_2015(2).pdf

COSALFA. Informe de la secretaria ex officio a la $38^{a}$ reunión de la Comisión Sudamericana de Lucha Contra la Fiebre Aftosa. Recife, 31/03/2011 a 1\%/04/2011.2011 
FISH, E.N. The X-files in immunity: sex-based differences predispose immune responses. NatReviews Immunology, v.8, n.9,p. 737-744, 2008.

LYRA, T.M.P. A febre aftosa no Brasil: evolução e determinantes das políticas públicas de controle e erradicação, 1950-2002. 2003. 130 f. Tese (Doutorado em Ciência Animal) - Universidade Federal de Minas Gerais, Belo Horizonte, 2003.

LYRA, T.M.P; CÔRTES, J.A. O diagnóstico sorológico de febre aftosa em países que praticam a vacinação. Revista Brasileira de Medicina Veterinária, v.29, n.4, p.142-148, 2007.

MARQUES, G.H.F. A experiência brasileira no combate a febre aftosa: emprego do sistema I-ELISA 3ABC/EITB para certificação sanitária de bovídeos e bubalinos, 2013, 66 p. Dissertação de Mestrado em Sanidade, Segurança Alimentar e Ambiental no Agronegócio, Instituto Biológico. São Paulo, 24.04.2013. http://www.biologico.sp.gov.br/ pos_graduacao/teses_2013/guilherme.php.Acesso em: 11 nov. 2015.

MARQUES, G. H. F; DE STEFANO, E; PITUCO, E. M. Sorodiagnóstico de febre aftosa por ELISA 3ABC/EITB em bovinos sistematicamente vacinados no período de 2001 a 2010 , Brasil. 24a RAIB. Biológico, São Paulo, v.73, n.2, p.129-176, jul./dez., 2011 . Disponível em: http://www.biologico.sp.gov.br/docs/bio/v73_2/p131. pdf. Acesso em 18 jun. 2015.
OIE. WORLD ORGANIZATION FOR ANIMAL HEALTH. Zonificación y Compartimentación. In: Códigoanitario para los animales terrestres. Artículo 4.3.1. Paris: OIE; 2014. Disponível em: <http://www. oie.int/index.php?id=169\&L=2\&htmfile=chapitre_zoning_ compartment.htm>. Acesso em: 18 jun. 2015.

OIE. WORLD ORGANIZATION FOR ANIMAL HEALTH. Infection with foot and mouth disease virus. In: Terrestrial Animal Health Code. Chapter 8.8. Paris: OIE; 2015. Disponível em: http://www. oie.int/index.php?id=169\&L=0\&htmfile=chapitre_fmd.htm. Acesso em: 08 dez. 2015.

PINHEIRO, I.; DEJAGER, L.; LIBERT, C. X-chromosome-located microRNAs in immunity: Might hey explain male/female differences? Bioessays, v.33, n.11, p. 791-802, 2011.

SOUZA, J.G.; DÔLIVEIRA, C.F.D.; NOGUEIRA, J.M.;M. MACHADO, J.C.; FIGUEIREDO, V.C.F. ABC do Programa Nacional de Prevenção e Erradicação da Febre Aftosa. Brasília: MAPA; 1994.

WORLD TRADE ORGANIZATION - WTO. Sanitary and phytosanitary measures: text of the agreement. The WTO Agreement on the Application of Sanitary and Phytosanitary Measures (SPS Agreement). Disponível em: https://www.wto.org/english/tratop_e/ sps_e/spsagr_e.htm. Acesso em: 08 dez. 2015. 